\section{Opinions Regarding the Value and Use of the AMCP Format Still Unknown}

Prior research has demonstrated the importance of pharmacoeconomics in drug research and formulary decisions. ${ }^{1,2,3} \mathrm{~A}$ recent JMCP letter to the editor from Lyles and Watkins encouraged increased assessments on the use of the AMCP Format for Formulary Submissions that produce clear inferences concerning the relationship between the dossier and subsequent formulary decisions.$^{4}$ However, surprising little evidence of the impact of the AMCP Format and dossiers on drug formulary decisions is evident given that only one recent account by Spooner et al. exists detailing the real-world use of the AMCP Format. ${ }^{5}$

In a previous issue of JMCP, Nichol et al. surveyed representatives from managed care organizations (MCOs) and pharmaceutical manufacturers regarding their opinions of the AMCP Format. ${ }^{6}$ The results of this survey research are timely because they shed some light on the formerly unpublished perspectives of these representatives. Furthermore, because the survey was conducted from September 2004 to October 2005, these opinions coincide with the introduction of Version 2.1 of the AMCP Format for Formulary Submissions released in April 2005.7 It must be noted, however, that Version 2.1 had just been released and that the survey participants were likely responding based on their experience with the past version.

The Nichol et al. article is a "small survey" of MCOs and pharmaceutical manufacturers. The $20 \mathrm{MCO}$ respondents surveyed came from a sample of both large and small companies from the National Directory of Managed Care Organizations database. The majority (70\%) of the MCO respondents held the position of pharmacy director, responsible for evaluating dossiers and compiling/presenting the data to pharmacy and therapeutics committees. The 7 survey participants from pharmaceutical firms were all members of the Pharmaceutical Research and Manufacturers of America Foundations Health Outcomes Committee, which is composed of directors of health outcomes departments who have experience in developing dossiers in accordance with the AMCP dossier guidelines. Therefore, it cannot be assumed that they are representative of pharmaceutical manufacturers as a whole. There may be substantial differences in the opinions of employees of pharmaceutical manufacturers compared with this select group of directors.

It is surprising that only $40 \%$ of all drugs reviewed by MCOs included dossiers from the manufacturer. In their evaluation of pharmaceutical manufacturers' responses to a request for a product dossier prepared using the AMCP Format, Spooner et al. noted that dossiers were received for only 58\% of the products for which dossiers were requested. ${ }^{5}$ Nichol et al. did not report on the number and percentage of drugs for which dossiers had been developed and submitted to MCOs by the companies represented by respondents in their survey of manufacturer representatives.
Nichol et al. stated that $54 \%$ of the dossiers received by MCOs included budget impact models and 39\% included other forms of economic analysis (cost-effectiveness or cost-benefit analyses). Nearly half of these models appeared to be cost-effectiveness evaluations, and a small number were reported to be tailored to the MCO's population. Spooner et al. claimed that $68 \%$ of the dossiers received by one MCO included a pharmacoeconomic or disease management impact model. ${ }^{5}$ Approximately half of the dossiers in the Nichols et al. study contained economic models that were regarded as being adequate by MCOs. In the Spooner et al. study, $20 \%$ of the models were unlocked, interactive budget impact models, whereas the other $48 \%$ essentially contained only reports on the analysis performed instead of actual models. ${ }^{5}$ Better communication between pharmaceutical manufacturers and MCOs appears to be the solution for the production of models that offer more value to MCOs to facilitate their decision to include/exclude drugs on their formularies.

Nichol et al. found that small and large MCOs varied considerably in their opinions as to whether the economic models presented in the dossiers were adequate. Three fourths of the MCO respondents claimed to have the capacity to develop or evaluate the economic models, and approximately one third mentioned that they typically varied the assumptions of the models that permitted evaluation.

Dossier confidentiality is clearly an area of concern for pharmaceutical manufacturers due to the lack of assurances by MCOs regarding this confidentiality. Given the business relationship between pharmaceutical manufacturers and MCOs, it seems unlikely that a manufacturer would attempt to benefit by pursuing legal action against an MCO concerning a breach of confidentiality related to a dossier.

Information presented in the Nichol et al. article contributes to the conclusion that the overall perceived value of the AMCP dossier format appears to be divided: certain MCOs seem to feel that dossiers should be used in their decision-making process, whereas others fail to see the value they provide. Pharmaceutical manufacturers viewed dossiers as a vehicle in which to convey the value of their products.

Going forward, it is interesting to note the divided (50/50) opinion of pharmaceutical manufacturers as to whether the new AMCP guidelines will improve the submission process as well as the transmission of data and information from pharmaceutical manufacturer to MCO. Pharmaceutical manufacturers expected that other groups besides MCOs, such as pharmacy benefit managers and Centers for Medicare and Medicaid Services, would use either a framework similar to the AMCP Format or the existing AMCP Format.

Besides inferring that the opinions of manufacturer representatives in the survey by Nichol et al. are most likely not representative of the opinions of employees of manufacturers in general, the question of the usefulness of the AMCP Format has not been answered by this research. Further research is war- 
ranted, including additional case reports such as that described by Spooner et al., in the quest to maximize the usefulness and utilization of the AMCP Format.

\author{
Carl V. Asche, PhD \\ Research Associate Professor \\ Director of Graduate Studies \\ Department of Pharmacotherapy \\ University of Utah College of Pharmacy \\ 421 Wakara Way, Suite 208 \\ Salt Lake City, UT 84108 \\ carl.asche@pharm.utah.edu
}

\title{
DISCLOSURES
}

The author discloses no potential bias or conflict of interest relating to the subject of this article.

\section{REFERENCES}

1. DiMasi JA, Caglarcan E, Wood-Armany M. Emerging role of pharmacoeconomics in the research and development decision-making process. Pharmacoecon. 2001;19(7):753-66.

2. Fullerton P, Atherly DS. Formulary development at Regence BlueShield a formula for success. Value Health. 2002;5(4):297-300.

3. Watkins JB, Minshall ME, Sullivan SD. Application of economic analyses in U.S. managed care formulary decisions: a private payer's experience. J Manag Care Pharm. 2006;12(9):726-35. Available at: http://www.amcp.org/data/jmcp/ 726-735.pdf.

4. Lyles A, Watkins JD. Manufacturer response to AMCP Format dossier requests. J Manag Care Pharm. 2007;13(3):290-91; author reply 291-92. Available at: http://www.amcp.org/data/jmcp/290-921.pdf.

5. Spooner J, Gandhi PK, Connelly SB. AMCP Format dossier requests: manufacturer response and formulary implications for one large health plan. J Manag Care Pharm. 2007;13(1):37-43. Available at: http://www.amcp.org/ data/jmcp/37-43.pdf

6. Nichol MB, Knight TK, Epstein J, Honda DH, Tretiak R. Opinions regarding the Academy of Managed Care Pharmacy dossier submission guidelines: results of a small survey of managed care organizations and pharmaceutical manufacturers. J Manag Care Pharm. 2007;13(4):360-71. Available at: http:// www.amcp.org/data/jmcp/360-71.pdf.

7. Foundation for Managed Care Pharmacy. The AMCP Format for Formulary Submissions. Version 2.1. A format for support of formulary consideration by health care systems in the United States. Alexandria, VA: Academy of Managed Care Pharmacy; April 2005. Available at: www.fmcpnet.org/cfr/waSys/f.cfc?method= getListFile\&id=A2D0F502. 